\title{
Molecular Sizes of Phenothiazines taken upon the Adsorption from Aqueous Solution and upon the Permeation through Cellulose Membrane ${ }^{1,2)}$
}

\author{
Naoki Nambu, ${ }^{3 a)}$ Tsuneji Nagai ${ }^{3 b}$ and Hisashi Nogami ${ }^{3)}$ \\ Faculty of Pharmaceutical Sciences, University of Tokyo ${ }^{3)}$
}

(Received November 12, 1970)

Mechanisms of pharmacological actions of phenothiazines have been known to be more or less based on the membrane actions. ${ }^{4,5)}$

As in vitro studies of the membrane action, there have been often discussed the area occupied by one molecule of each phenothiazine compound at an interface, which is also important in discussing the interaction with other drugs at the interface. ${ }^{6}$ )

The present study was attempted to obtain the area occupied by one molecule of phenothiazines upon the adsorption from aqueous solution and the cross-sectional area evaluated from Stokes' radius of the molecule upon the permeation through cellulose membrane, discussing the results in comparison with the existing data concerning the similar values obtained from surface activity, ${ }^{7-9)}$ the maximal stabilization of erythrocyte membrane ${ }^{10}$ and the steric structure. ${ }^{7,9)}$

\section{Experimental}

Materials-Phenothiazines used were the same as those in previous papers.1,11) Carbon black (CB) and silica gel (SG) of specific surface area $1250 \mathrm{~m}^{2} / \mathrm{g}$ and $282 \mathrm{~m}^{2} / \mathrm{g}$, respectively, ${ }^{12}$ ) were the same as those in a previous paper. ${ }^{11)}$

Determination of the Adsorbed Amount of Phenothiazines by Batch Method_-This was done at $\mathrm{pH}$ 6.00 at $30^{\circ}$ in the same way as described in the previous paper. ${ }^{11)}$

Determination of the Permeability of Phenothiazines through Cellulose Membrane_-This was done at $\mathrm{pH} 6.00$ at $30^{\circ}$ in the same way as described in the previous paper. ${ }^{1)}$

\section{Result and Discussion}

The area occupied by one molecule of each phenothiazine compound was calculated from the specific surface area of adsorbent and Langmuir constant a which is the amount adsorbed

1) This paper forms Part XXI of "Physico-chemical Approach to Biopharmaceutical Phenomena." Preceding paper, Part XX: N. Nambu, T. Nagai, and H. Nogami, Chem. Pharm. Bull. (Tokyo), 19, 808 (1971).

2) A part of this work was presented at 90th Annual Meeting of the Pharmaceutical Society of Japan, Sapporo, July 1970.

3) Location: Hongo, Bunkyo-ku, Tokyo; a) Present address: Pharmaceutical Research Laboratory, Tanabe Seiyaku Co. Ltd., Kashima-cho, Higashi-Yodogawa-ku, Osaka; b) To whom communications should be directed.

4) a) G. Zografi, D.E. Auslander and P.L. Lytell, J. Pharm. Sci., 53, 573 (1964); b) G. Zografi and D.E. Auslander, ibid., 54, 1313 (1965).

5) a) M.A. Spirtes and P.S. Guth, Biochem. Pharmacol., 12, 37 (1963); b) A.R. Freeman and M.A. Spirtes, ibid., 12, 47 (1963); c) Idem, ibid., 12, 1237 (1963).

6) a) G. Zografi, D.E. Auslander and P. L. Lytell, J. Pharm. Sci., 53, 573 (1964); b) G. Zografi and D.E. Auslander, ibid., 54, 1313 (1965).

7) F. Vilallonga, E. Fried and J.A. Izquierdo, Arch. Int. Pharmocodyn. Therap., 130, 260 (1961).

8) G. Zografi and I. Zarenda, Biochem. Pharmacol., 15, 591 (1966).

9) P.M. Seeman and H.S. Bialy, Biochem. Pharmacol., 12, 1181 (1963).

10) P. Seeman and J. Weinstein, Biochem. Pharmacol., 15, 1737 (1966).

11) H. Nogami, T. Nagai and N. Nambu, Chem. Pharm. Bull. (Tokyo), 18, 1643 (1970).

12) Determined by BET method using nitrogen. 
TABLE I. Occupied Area by or Cross-Sectional Area of One Molecule of Phenothiazines in $\AA^{2} /$ molecule evaluated by Various Methods

\begin{tabular}{|c|c|c|c|c|c|c|c|c|}
\hline \multirow{2}{*}{$\begin{array}{l}\text { Method } \\
\text { Compound }\end{array}$} & \multicolumn{2}{|c|}{$\begin{array}{l}\text { Adsorption from } \\
\text { aqueous solution }\end{array}$} & \multicolumn{2}{|c|}{$\begin{array}{l}\text { Permeation through } \\
\text { cellulose membrane }\end{array}$} & \multicolumn{3}{|c|}{ Surface activity } & \multirow{2}{*}{$\begin{array}{l}\text { Maximal } \\
\text { stabilization of } \\
\text { erythrocyte } \\
\text { membrane }^{d)}\end{array}$} \\
\hline & $\mathrm{CB}$ & SG & $r(\overparen{\AA})$ & $S$ & Vila. $\left.{ }^{a}\right)$ & Zogr. ${ }^{b)}$ & $\overline{\text { Seem. }}^{c)}$ & \\
\hline Anergen & 98 & 1129 & 5.78 & 105 & & & & \\
\hline Diethazine & 106 & 833 & 7.42 & 173 & 67 & & 87 & \\
\hline Promazine & 106 & 1060 & 6.19 & 120 & 66 & 65.5 & 87 & \\
\hline Chlorpromazine & 101 & 758 & 6.70 & 141 & & 66.3 & 87 & 100 \\
\hline Triflupromazine & 86 & 656 & 7.24 & 165 & & 69.5 & 87 & \\
\hline Promethazine & 106 & 1690 & 6.22 & 122 & 46 & 77.0 & 87 & 65 \\
\hline Alimemazine & 111 & 1550 & 6.28 & 124 & & & & \\
\hline Levopromazine & 146 & & 7.00 & 154 & & & & \\
\hline Methodilazine & 93 & 1273 & 6.53 & 134 & & & & \\
\hline Perazine & 210 & 164 & 7.10 & 158 & & & & \\
\hline Prochlorperazine & 107 & 94 & 7.38 & 171 & & & & \\
\hline Trifluoperazine & 103 & 56 & 8.06 & 204 & & & 87 & 145 \\
\hline Chlorpromazine sulfoxide & 168 & 742 & 7.06 & 157 & & & & \\
\hline Isothipendyl & 172 & 1834 & 6.12 & 118 & & & & \\
\hline
\end{tabular}

a) by Vilallonga, et al. ${ }^{7)}$; air- $0.1_{\mathrm{M} \mathrm{HCl}} \mathrm{Hinterface}$ at great pressure at $20^{\circ}$

b) by $\mathrm{Zografi}$ and $\left.\mathrm{Zarenda}{ }^{8}\right)$; air- $(0.01 \mathrm{M} \mathrm{HCl}+0.09 \mathrm{M} \mathrm{NaCl}, \mathrm{pH} 2.00)$ interface at $25^{\circ}$

c) by Seeman and Bialy"); air-Ringer solution interface at $23^{\circ}$

d) by Seeman and Weinstein ${ }^{10)}$; the area of the erythrocyte membrane associated with one molecule

when the entire surface is covered by a monolayer. ${ }^{11)}$ The results for the present compo inds are shown in Table I.

The Stokes' radius, $r$, was calculated from the diffusion constant through cellulose membrane, $D,{ }^{1)}$ according to the following equation (1).

$$
r=\frac{k T}{6 \pi \eta_{0}} \cdot \frac{1}{D}=2.612 \times 10^{-13} \frac{1}{D}
$$

where $\boldsymbol{k}$ is Boltzman constant $\left(1.38 \times 10^{-6} \mathrm{erg} \cdot \mathrm{deg}^{-1}\right), \eta_{0}$ the viscocity of the solvent $(8.50 \times$ $\left.10^{-3} \mathrm{~g} \cdot \mathrm{cm}^{-1} \cdot \mathrm{sec}^{-1}\right)$, and $T$ the absolute temperature $\left(303^{\circ} \mathrm{K}\right)$. The values of the cross-sectional area, $S$, calculated from $r$ are shown together with the values of $r$ in Table I.

There are also listed in Table I the existing data concerning the area occupied by one molecule obtained from the surface activity ${ }^{7-9}$ and the area of the erythrocyte membrane associated with one molecule upon the maximal stabilization. ${ }^{10}$

Although the cross-sectional area of phenothiazine ring may differ with its conformation, the value has been reported as $60 \AA^{2}{ }^{9)}$ or $66-70 \AA^{2}{ }^{7}$ ) The occupied area by one molecule upon the adsorption by $\mathrm{CB}$ was a little larger than the cross-sectional area of a phenothiazine molecule evaluated from its steric structure mentioned above. This result was considered due to the adsorption of water on $\mathrm{CB}$, which may be desorbed with the addition of $\mathrm{NaCl}$ to result in a decrease in the occuped area to approach the cross-sectional area evaluated from its steric structure, as the data for promazin are shown in Table II.

TABLE II. Effect of $\mathrm{NaCl}$ on the Occupied Area by One Molecule of Promazine upon Adsorption by $\mathrm{CB}$

\begin{tabular}{cc|cc}
\hline \hline $\begin{array}{c}\text { Concentration } \\
\text { of } \mathrm{NaCl}(\mathrm{M})\end{array}$ & $\begin{array}{c}\text { Occupied area } \\
\left(\AA^{2}\right)\end{array}$ & $\begin{array}{c}\text { Concentration } \\
\text { of } \mathrm{NaCl}(\mathrm{M})\end{array}$ & $\begin{array}{c}\text { Occupied area } \\
\left(\AA^{2}\right)\end{array}$ \\
\hline 0 & 106 & 1.0 & 97 \\
0.5 & 102 & 1.5 & 92 \\
\hline
\end{tabular}


Anyhow, the surface of $C B$, a very hydrophobic adsorbent, is considered to be covered by a monolyaer of phenothiazine molecules as is expressed by Langmuir equation. The interfaces concerning the existing data shown in Table I also seem to be covered by a monolayer of phenothiazine molecules. On the other hand, SG is so hydrophilic that it may adsorb a large amount of water and offer a small area effective to the adsorption of phenothiazine molecules.

The values of cross-sectional area of phenothiazines calculated from Stokes' radius upon the permeation through cellulose membrane were a little larger than that evaluated from its steric structure. However, this result may be accepted on the consideration that a phenothiazine molecule takes a long and slender conformation upon the permeation through cellulose membrane. ${ }^{13)}$ In other words, it is unreasonable to assume a phenothiazine melecule to be cubic upon calculating the cross-sectional area.

According to Teller and Denber's molecular biological investigation, ${ }^{14)}$ a phenothiazine molecule may take a flexible conformation upon the permeation into biological membrane or upon the binding to protein, coming into a pore of about $7.5 \AA$ in size in the protein layer of biological membrane, as is related to an onset of the tranquilizing effect. Since the size of a phenothiazine molecule evaluated from the adsorption on $\mathrm{CB}$ or from the permeation through cellulose membrane was considered to be common to that in biological membrane such as mentioned above, it was suggested in addition to the previous works ${ }^{1,11}$ ) that various physico-chemical investigations regarding the behavior of phenothiazine molecules upon the adsorption from aqueous solution or upon the permeation through model membrane might give useful informations for understanding of biopharmaceutical phenomena.

Acknowledgement The authors gratefully acknowledge the award of Research Grants from Naito Foundation (to T.N.). Thanks are also given for the generous supports of the materials to Banyu Pharmaceutical Co., Ltd., Daiichi Pharmaceutical Co., Ltd., Dainippon Pharmaceutical Co., Ltd., Nippon Squibb Co., Ltd., Sumitomo Chemical Co., Ltd., and Yoshitomi Pharmaceutical Co., Ltd.

13) S. Yamabe, "Iyakuhin Bunshiron," Asakura-shoten, Tokyo, 1968.

14) D.N. Teller and H.C.B. Denber, "Diseases of the Nervous System," GWAN, Suup., 29,93 (1968).

[Chem. Pharm. Bull.

\title{
1,3,6,8-Tetramethyl-2,4,5,7 (1H,3H,6H,8H)pyrimido[5,4-g]pteridinetetrone and 1,3,5,7-Tetramethyl-2,4,6,8(1H,3H,5H,7H)- pyrimido $[4,5-g]$ pteridinetetrone
}

\author{
Fumio Yoneda and Sadao Nishigaki
}

Pharmaceutical Institute, Keio Gijuku University ${ }^{1)}$

(Received November 14, 1970)

1,3,6,8-Tetramethyl-2,4,5,7 $(1 \mathrm{H}, 3 \mathrm{H}, 6 \mathrm{H}, 8 \mathrm{H})$ pyrimido[5,4-g]pteridinetetrone $\left.(\mathrm{I})^{2}\right)$ is the common product which has frequently been observed during the reactions using 6-amino-1,3-

1) Location: 35, Shinanomachi, Shinjuku-ku, Tokyo.

2) E.C. Taylor, C.K. Cain, and H.M. Loux, J. Am. Chem. Soc., 76, 1874 (1954). 